\title{
Políticas de reconhecimento uma novidade das políticas sociais do PT?
}

Paulo J. Krischke*

A eleição de Luis Inácio Lula da Silva para a Presidência do Brasil suscitou, entre os eleitores brasileiros e observadores do mundo inteiro, muitas expectativas no sentido da justiça social e da redistribuição da renda. No campo internacional (e talvez também entre parte dos seus eleitores brasileiros) a campanha presidencial de Lula parecia prometer (ou ameaçar) um ressurgimento do populismo - como nas experiências do passado, do "modelo Vargas/Goulart", com suas políticas de confrontação interna e externa, redistributivismo irresponsável e descontrole inflacionário. ${ }^{1}$ Tanto assim que os dados macro-econômicos, durante como logo após a campanha de Lula, evidenciavam as pressões internacionais, o nervosismo do mercado e o iminente retorno da inflação. Contudo, essas previsões catastróficas não se confirmaram, tendo passado quase dois anos das eleições.

* Doutorado Interdisciplinar em Ciências Humanas, Universidade Federal de Santa Catarina, Brasil. E-mail: krischke@brturbo.com

1 Sobre o "ressurgimento do populismo" na América Latina ver Torre (1998) e Knight (1998).

Civitas

Porto Alegre

v. 4

\begin{tabular}{l|l} 
n. 2 & jul.-dez. 2004
\end{tabular}

p. $337-352$ 
O novo governo tem mantido o equilíbrio macro-econômico nas contas externas do país, a ponto de receber apoios do FMI e credores estrangeiros. $\mathrm{O}$ ponto forte destes primeiros anos do governo tem sido o das reformas no âmbito administrativo (previdenciário, tributário, etc.), cuja discussão iniciou no governo anterior, mas que só nesta gestão começaram a implementar-se. É certo que a principais medidas de políticas sociais e redistribuição da renda ficaram aparentemente restritas ao remanejo e centralização das políticas compensatórias de combate à pobreza, herdadas do governo anterior. Mas note-se que não obstante as reclamações de alguns sindicatos, e de outros setores mais à esquerda do PT, sobre as expectativas de redistribuição imediata, o bloco de partidos e movimentos (e segundo as pesquisas, a maioria dos eleitores) que elegeu Lula permanece inalterado em seu apoio ao governo (chegando mesmo esse apoio a expandir-se entre os setores de centro do espectro partidário). ${ }^{2}$

Por certo, as previsões catastróficas da época da campanha eleitoral, de uma regressão ao populismo, podem sempre retornar (e confirmar-se), se o país sofrer uma crise econômica, e de agitação social e política, recaindo no isolamento internacional - caso em que as negociações com o FMI, a ALCA, e principalmente com os Estados Unidos entrariam em colapso. Porém, até o momento nem o redistributivismo econômico nem as negociações internacionais têm apresentado o perfil crítico que alguns analistas aguardavam. Sem dúvida vários fatores têm contribuído para essa conjuntura favorável durante a primeira metade do governo Lula. Sem entrar na discussão desses fatores, este trabalho faz apenas uma discussão inicial sobre a interpretação da política social que parece estar prevalecendo nas orientações do governo e nas expectativas da população.

Esta discussão se apóia na teoria da justiça proposta por Nancy Fraser, a qual enfatiza as políticas de reconhecimento sociopolítico-cultural, em contraste com as políticas apenas de redistribuição econômica (ainda que estas últimas se relacionem com as primeiras, nesse contexto conceptual). Em suma, segundo essa autora, a distinção entre reconhecimento e redistribuição é apenas uma distinção analítica ou conceptual, com vistas a uma melhor compreensão do alcance das políticas sociais do governo e dos seus efeitos na

2 É certo porém que as pesquisas de opinião, desde Junho de 2004, retratam uma queda no apoio ao governo e ao próprio Presidente, embora ainda mantendo pequena maioria. 
legitimidade e governabilidade. Num primeiro momento examinaremos alguns aspectos dessa teoria, passando logo a um resumo da trajetória do PT e seus efeitos na vitória de Lula. Finalmente consideraremos alguns dados de pesquisa sobre a mudança atual na cultura política brasileira, principalmente em comparação com os resultados das políticas participativas e de reconhecimento em algumas cidades, como Porto Alegre.

\section{O entrelaçamento entre reconhecimento e redistribuição nas políticas públicas ${ }^{3}$}

Nancy Fraser é quem melhor tem admitido os desafios do tratamento conjunto das políticas de reconhecimento e redistribuição na sociedade atual: "O discurso da justiça social, antes centrado na distribuição (econômica), agora se divide crescentemente entre as demandas de redistribuição, de um lado, e as demandas por reconhecimento, de outro. (Às vezes...) nos apresentam isso construído efetivamente como uma escolha excludente: redistribuição ou reconhecimento? Políticas de classe ou políticas de identidade? Social Democracia ou multiculturalismo? Essas são falsas antíteses, pois a justiça requer hoje tanto a redistribuição como o reconhecimento, uma vez que nenhum deles é por si só suficiente" (Fraser, 1999, p. 1). ${ }^{4}$

A seguir Fraser lança sua ressalva à conceptuação de Honneth (2003) sobre o reconhecimento:

3 Esta seção e a próxima resumem argumento desenvolvido em Krischke, 2003b. Agradeço os comentários recebidos de Ted Hewitt sobre este texto anterior, e também sobre o atual durante sua apresentação no Canadá, na Conferência de CALACS (outubro de 2004).

E acrescenta em seguida: "As soon as one embraces this thesis, however, the question of how to combine them becomes paramount. I contend that the emancipatory aspects of the two paradigms need to be integrated in a single, comprehensive framework. In moral philosophy, the task is to devise an overarching conception of justice that can accommodate both defensible claims for social equality and defensible claims for the recognition of difference. In social theory, the task is to understand the complex relations between interest and identity, economy and culture, and (as I shall suggest) class and status in contemporary society. In political theory, the task is to envision a set of institutional arrangements and associated policy reforms that can remedy both maldistribution and misrecognition, while minimizing the mutual interferences likely to arise when the two sorts of redress are sought simultaneously. In practical politics, finally, the task is to foster democratic engagement across current divides in order to build a broad-based programmatic orientation that integrates the best of the politics of redistribution with the best of the politics of recognition". 
Axel Honneth e Charles Taylor, dois dos principais teóricos do reconhecimento, o interpretam como uma questão de autoestima. Considero, ao contrário, que é uma questão de justiça [...] O que torna o não-reconhecimento um erro moral é a sua negativa a indivíduos e grupos da possibilidade de participação parietária com os demais numa interação social [...] Essa norma parietária apela a uma concepção de justiça que pode ser aceita por pessoas que aderem a visões doutrinárias divergentes, desde que concordem assumir termos eqüitativos de interação sob condições de pluralismo valorativo (Ibid., p. 5)

Honneth, por sua vez, responde à pecha de "psicologismo" ao defender uma diferença entre a precedência "genética" (a origem do não-reconhecimento na relação moral interpessoal) e a precedência "léxica" (a sustentação institucional dessa relação no sistema jurídico), onde pode ser prioritariamente corrigida. $\left(2003^{\mathrm{a}}\right)$. Embora Honneth enfatize essa prioridade léxica do reconhecimento jurídico sobre as formas subjetivas de reconhecimento, a generalidade desse procedimento é vulnerável à crítica de "universalismo abstrato". No dizer de Fraser, a questão deve ser abordada

no espírito do pragmatismo informado pelos "insights" da teoria social crítica. Desta perspectiva o reconhecimento é uma reparação à injustiça, e não a satisfação de uma necessidade genérica [...] Assim, as formas de reconhecimento exigidas pela justiça em cada caso, dependem das formas de não-reconhecimento que demandam reparação (Ibid., p. 8). ${ }^{6}$

5 "Treating recognition as a matter of justice has a second advantage as well. It conceives misrecognition as a status injury whose locus is social relations, not individual psychology. To be misrecognized, on this view, is not simply to be thought ill of, looked down on, or devalued in others' conscious attitudes or mental beliefs. It is rather to be denied the status of a full partner in social interaction and prevented from participating as a peer in social life as a consequence of institutionalized patterns of cultural value that constitute one as comparatively unworthy of respect or esteem. This approach avoids difficulties that arise when misrecognition is understood psychologically. When misrecognition is identified with internal distortions in the structure of self-consciousness of the oppressed, it is but a short step to blaming the victim. Conversely, when misrecognition is equated with prejudice in the minds of the oppressors, overcoming it seems to require policing their beliefs, an approach that is authoritarian. On the justice view, in contrast, misrecognition is a matter of externally manifest and publicly verifiable impediments to some people's standing as full members of society. And such arrangements are morally indefensible whether or not they distort the subjectivity of the oppressed."

6 "The approach proposed here sees claims for the recognition of difference pragmatically and contextually - as remedial responses to specific harms. Putting questions of justice at the center, it appreciates that the recognition needs of subordinate groups differ from those of dominant groups; and that only those claims that promote participatory parity are morally 
Este debate sobre os desafios das políticas de redistribuição e reconhecimento deve sem dúvida continuar, como atesta o livro recente em coautoria de Nancy Fraser e Axel Honneth. As suas conhecidas diferenças teóricas tendem a assumir ali a validade recíproca de suas respectivas contribuições, bem como os pontos que sustentam em comum (Fraser e Honneth, 2003). ${ }^{7}$ De um ponto de vista prático, e na visão pragmática defendida por Fraser, cabe considerar a trajetória do PT acerca dessas políticas, tanto na sua origem sindical, como nas políticas públicas que tem implementado até aqui.

\section{O PT e a expansão da cidadania no Brasil}

Nunca é demais recordar que as políticas de redistribuição econômica por exemplo, demandadas pelas greves que instituíram o "novo sindicalismo" ao final dos anos setenta no Brasil - tiveram também estreita relação com a emergência de uma defesa dos direitos de cidadania, no plano do reconhecimento das identidades dos trabalhadores. Esse duplo questionamento iniciou com a decadência da ditadura militar, e com amplo e crescente apoio da sociedade civil. Já argumentei em outra parte que,

Não é de surpreender que o governo militar da época considerasse subversivas as greves industriais do final dos anos 70 - não apenas porque os sindicatos atuaram livremente na defesa estratégica dos salários e direitos consagrados pela legislação trabalhista, mas também porque defenderam as liberdades democráticas em seu conjunto. (... Esse precedente normativo era negado pela ditadura, mas) os direitos já publicamente reconhecidos pela legislação trabalhista, e sua reivindicação prática por parte dos sindicatos, proporcionaram o fundamento institucional para o exercício desses direitos, e para a sua influência sobre a expansão de uma 'cultura de direitos' na esfera pública (Krischke, 2003a, p. 113).

justified. For the pragmatist, accordingly, everything depends on precisely what currently misrecognized people need in order to be able to participate as peers in social life. And there is no reason to assume that all of them need the same thing in every context" (Ibid.).

7 Em sua entrevista Honneth afirma que "nas questões normativas concordamos mais do que era claro no início. Nós dois entendemos que o objetivo da justiça social é possibilitar a participação de todos os membros da sociedade no processo comunicativo da vida em sociedade [...] Em relação à questão central, redistribuição ou reconhecimento, a diferença consiste em que eu somente vejo a possibilidade de justificar as finalidades da redistribuição através das categorias do reconhecimento social" (2003a). 
Por outra parte, não é possível entender a trajetória de Luis Inácio Lula da Silva, ${ }^{8}$ sua liderança na evolução do PT, e seu desempenho no atual governo, sem incluir o aprendizado prático e político dos processos de negociação, generalizado pela CUT desde os anos oitenta entre os sindicatos filiados, através de suas "escolas sindicais". ${ }^{9}$ Este processo foi inicialmente assessorado pelo sindicalismo Social-Democrático europeu, e resultou em políticas "consociativas" ou de "concertação", as quais envolveram conjuntamente políticas de reconhecimento e de redistribuição. No dizer de um intérprete desse processo para a América Latina como um todo:

La integración de actores en sistemas de negociación presupone que se reconozcan mutuamente como actores políticos legítimos. En los contextos posautoritarios en América Latina, esta legitimación mutua entre los actores ha constituido una de las funciones principales de las politicas de concertación (Schedler, 1992, p. 24).

Uma vez iniciado, esse processo de reconhecimento mútuo e negociação econômica, que começou entre os sindicatos e as patronais, não cessou de difundir-se a outros setores da sociedade, alcançando aos poucos a esfera pública do sistema político institucionalizado. Isto ocorreu no Brasil, em grande parte, como resultado das gestões municipais e estaduais do PT em várias regiões do país, envolvendo também amplos setores de outros partidos e da sociedade civil organizada. Hoje, por exemplo, existem conselhos consultivos em muitos órgãos e serviços públicos federais e estaduais, envolvendo a participação de usuários desses serviços, ao lado de dirigentes públicos, e representantes de trabalhadores e empresários que operam nessas áreas.

Não é necessário examinar aqui as minúcias dessas experiências de participação, que como no caso do Orçamento Participativo de Porto Alegre, têm sido avaliadas pela literatura já vasta sobre o tema, ${ }^{10}$ como uma das principais fontes de legitimidade e governabilidade das administrações do PT - um dos motivos de sua contínua recondução ao governo, por quatro vezes consecutivas naquela cidade. Quero apenas salientar que nessa

\footnotetext{
8 Ver de Eder Sader (1988), o balanço da trajetória inicial de Lula nos anos setenta-oitenta.

9 Ver sobre isto o livro de Paulo Tumolo, 2002, que apresenta e critica os dados sobre o período.

10 Ligia Luhmann (2002) faz um balanço e revisão dessa bibliografia.
} 
experiência convergem elementos de políticas de redistribuição sócioeconômica com políticas sócio-culturais de reconhecimento entre as diferenças de identidade. Em outras palavras: há no orçamento participativo não só uma abertura de oportunidades de acesso (e redistribuição) à riqueza social (o orçamento da cidade), mas também de participação diferenciada no processo decisório (ainda que formalmente apenas em caráter consultivo). Nesse processo os participantes são reconhecidos na condição de cidadãos dotados de direitos e obrigações, com seus diferentes interesses, gostos e prioridades sociais e culturais. Aqueles que participam ativamente são chamados a intervir nas decisões sobre as prioridades da cidade como um todo, e não apenas sobre aquelas que interessam diretamente à vizinhança ou setor social a que pertencem.

É certo que há falhas e tropeços nesse processo, e não têm faltado opositores às experiências municipais de orçamento participativo, ${ }^{11}$ principalmente mas não apenas, entre as elites que sentem-se alijadas de seu habitual monopólio do poder. Os estudos sobre Porto Alegre têm constatado que mesmo os partidos de oposição ao PT tiveram que assumir, pelo menos nominalmente, compromissos de campanha que passaram a reconhecer os direitos de participação da cidadania. (Pinto, 1997) Sem duvida há nessas experiências uma convergência, que acresce (e partilha) substancialmente as funções governativas, e parece tornar-se indispensável à legitimidade e governabilidade na política contemporânea (e não apenas no Brasil). ${ }^{12}$

É necessário reconhecer que há um vasto desafio de pesquisa, ainda a realizar, face à complexidade do campo teórico que vem trabalhando a importância das políticas de distribuição sócio-econômica em suas relações com as políticas de reconhecimento sócio-cultural e político. Nem tudo o

11 Denis Rosenfield (2002), critica principalmente a confrontação do OP com as atribuições do poder legislativo. Marcia Ribeiro Dias (2002) analisa as vulnerabilidades da precária institucionalização do OP.

Segundo Schedler, desse modo "[...] desviam-se do governo as aspirações sociais, pois na elaboração participativa das políticas públicas o Estado renuncia a certas atribuições que lhe são exclusivas, enquanto os atores sociais, sindicais, empresariais e partidários aceitam uma co-responsabilidade no planejamento e implementação dessas políticas" (Schedler, 1992, p. 4). É clara a lusão deste autor às políticas corporatuivas do "Welfare State" europeu, embora admita que na América Latina essas políticas de "concertação" alcançaram uma função principalmente "utópica", de preparação para a democracia. 
que tem sido feito pelos governos do PT se inclui no âmbito desse debate. $\mathrm{Na}$ verdade, podemos hoje dizer que há "muitos PTs", não só nas suas frações internas mas na diversidade das políticas que promove. Contudo, como vimos acima, há setores da trajetória do PT que têm logrado inovar significativamente no terreno dessas políticas, exatamente como resultado de sua origem marcada pela negociação em termos de "participação parietária" (no dizer de Fraser) - a qual tende a conjugar o respeito à diferença e ao reconhecimento mútuo, com a demanda pela redistribuição da riqueza social. Veremos agora indícios de que as experiências participativas e as políticas de reconhecimento da trajetória do PT se relacionam às transformações atualmente em curso na cultura política do país.

\section{Políticas de reconhecimento e cultura política ${ }^{13}$}

Consideraremos nesta secção dados levantados em 2003 sobre os valores preferenciais da juventude brasileira, ao lado dos valores prioritários levantados em 2001, entre a juventude de Curitiba e Porto Alegre - os quais já foram tratados em análise fatorial (Krischke, 2004a). É importante assinalar preliminarmente que a Tabela 1 não trata de cotejar todos os valores priorizados (e nem mesmo os que obtiveram maior adesão) nas duas pesquisas, mas seleciona apenas alguns valores que foram incluídos nas duas pesquisas, e alcançaram correlações significativas com outras questões, na pesquisa de 2001. Além disso, advertimos que não se pode comparar diretamente os resultados das duas pesquisas, porque seus objetivos, públicos pesquisados, plano amostral e demais características técnicas, são inteiramente diferentes. Mesmo assim, sem muito rigor e num plano superficial, o cotejo entre esses dados pode ser esclarecedor ao nosso tema.

13 Esta seção foi em parte extraída do trabalho "Perfil da Juventude Brasileira: Questões de Cultura Política e Participação Democrática” (Krischke, 2004b). 


\section{Tabela 1}

Prioridades de valores entre a juventude (\%)

\begin{tabular}{|l|l|c|c|c|l|}
\hline $\begin{array}{c}\text { Ordem de } \\
\text { prioridade }\end{array}$ & \multicolumn{1}{|c|}{$(15-24$ anos) } & $\begin{array}{c}\text { BRASIL } \\
2003\end{array}$ & $\begin{array}{c}\text { Curitiba } \\
2001\end{array}$ & $\begin{array}{c}\text { Porto Alegre } \\
2001\end{array}$ & (17-28 anos) \\
\hline 3 & Igualdade de oportunidade & 46 & 53 & 62 & "Igualdade" \\
\hline 5 & Temor a Deus & 44 & 28 & 10 & \\
\hline 7 & Dedicação ao trabalho & 37 & 35 & 29 & \\
\hline 8 & Respeito ao meio ambiente & 36 & 26 & 41 & \\
\hline 9 & Religiosidade & 29 & 24 & 8 & \\
\hline 10 & Liberdade individual & 27 & 32 & 46 & "Liberdade" \\
\hline 12 & Competência & 23 & 35 & 34 & \\
\hline Fontes: & Krischke, 2004b. & & & & Krischke, 2004a. \\
\hline
\end{tabular}

Os valores pesquisados em 2001 nem sempre foram os mesmos da pesquisa de 2003, como é o caso de "Igualdade" e "Liberdade", que estão mais especificados na última pesquisa. Mas na pesquisa em Curitiba e Porto Alegre, esses mesmos valores, e mais o "Respeito ao meio ambiente" tiveram bem maior adesão na última cidade (e não apenas entre os jovens). Enquanto outros valores, como "Temor a Deus" e "Religiosidade" tiveram maior adesão em Curitiba (e muito maior na pesquisa nacional) que em Porto Alegre - e "Dedicação ao trabalho" também obteve um pouco mais de adesão nacional e em Curitiba. O valor da "Competência" foi o único que obteve quase idêntica adesão nas duas cidades - ainda que adesão bem menor na pesquisa nacional Aliás, a Tabela 1 indica que, em geral, a pesquisa nacional captou adesão a valores mais próxima dos priorizados em Curitiba, e bem menor que as prioridades em Porto Alegre.

No entanto, sabemos que Curitiba e Porto Alegre são duas capitais da Região Sul que apresentam características semelhantes, demográficas, de desenvolvimento sócio-econômico, orçamento municipal, industrialização, urbanização - e dos indicadores do denominado "tripé da modernização" (Moisés, 1995): ocupação, escolaridade e renda. Sabemos contudo que há mais de dez anos as administrações municipais dessas duas capitais têm sido conduzidas por partidos políticos de orientações opostas no cenário político nacional (em Porto Alegre o PT, e em Curitiba o PFL ou seus aliados no pólo conservador/liberal do espectro ideológico). Ao levantar os contrastes entre os valores 
em cada cidade (conforme a Tabela 1, especificamente sobre a juventude), tratamos de correlacioná-los com outros dados sobre a atividade política dos entrevistados, e logramos estabelecer perfis bastante nítidos dos eleitores em ambas as cidades (ver nota 13).

No caso da juventude das duas cidades, pudemos constatar que há tanto semelhanças como diferenças. Quanto às semelhanças, os jovens partilham uma demanda por competência (que é bem menor na pesquisa nacional) associada à condução do desenvolvimento e da estabilidade econômica, como objetivo prioritário para o país. Isto está claramente associado também à busca dos jovens por novas oportunidades de emprego, durante o tempo livre disponível, e à escolha do valor "Dedicação ao trabalho". Outras semelhanças incluem: os valores do "Prazer", da "Auto-realização", "Alegria", e do "Respeito ao meio ambiente" associados ao emprego eventual do tempo livre em "Lazer e relações afetivas" - sendo o valor Meio Ambiente também, como seria de esperar, mais fortemente associado às atividades eventuais de "Defesa do Meio Ambiente", no uso desejável do tempo livre. Outra opção significativa dos jovens das duas cidades no uso do tempo livre, é a de ocupá-lo em "Atividades políticas" - escolha feita principalmente por aqueles que reconhecem em outras questões a preferência pela democracia, e a "Importância da política" em suas vidas.

Mas há também diferenças entre as atitudes dos jovens das duas cidades. Por exemplo, em Curitiba, a opção no tempo livre por "Atividades assistenciais" é importante para aqueles que escolheram os valores "Religiosidade" ou "Temor a Deus" - que não alcança significação em Porto Alegre. (Aliás, a adesão a estes valores foi também muito maior na pesquisa nacional.) Por sua vez, a seleção de "Atividades políticas" como opção de tempo livre em Curitiba, relaciona-se à escolha do valor da "Liberdade" - sendo que esta última escolha também se relaciona à opção pela Democracia, na preferência por regime político. Em Curitiba houve também uma correlação significativa entre a escolha do valor "Desenvolvimento econômico", e a ênfase na "Maior participação da população nas decisões importantes de governo", como alternativa entre os principais objetivos do país. Em Porto Alegre essa correlação não foi encontrada, (talvez porque a participação fosse considerada disponível?) e o valor do "Desenvolvimento econômico" apareceu associado ao reconhecimento da "Importância da política" e da tolerância social e política (reconhecimento do direito à diferença) - que é muito mais priorizado nesta cidade. 
Como podemos apreciar, as correlações entre as opções de valores e outros indicadores de adesão eventual - por exemplo: utilização desejável do tempo livre, ou de que "gostaria de participar" mesmo quando ainda não participa de determinadas atividades associativas e ações não-convencionais - fornecem indicações significativas sobre tendências potenciais à mudança. Essas indicações podem ser muito mais explicativas daqueles fenômenos inovadores, que caracterizam o exercício da cidadania em cada cidade, e que o exame apenas das atitudes políticas convencionais não consegue captar. Portanto, foi necessário adotar procedimentos de análise multivariada dos dados, de modo a examinar a configuração característica dos valores selecionados em cada cidade, e suas relações com as demais atitudes e orientações políticas assumidas pelos entrevistados.

Um procedimento que resultou muito produtivo foi a correlação (principalmente significativa em Porto Alegre) das opções de valores com as atividades de tempo livre, as atividades associativas, e os índices de tolerância. Talvez resultados semelhantes se obtenham também na pesquisa de 2003, correlacionando por exemplo, os índices de tolerância, ou reconhecimento do direito à diferença das minorias ("descriminalização do aborto $30 \%$; legalização da união entre pessoas do mesmo sexo - $25 \%$; descriminalização do uso de drogas - 17\%”), com os valores prioritários, atividades associativas e ações não-convencionais dos entrevistados. Com esses e outros procedimentos será possível chegar a configurações mais precisas da predominância dos valores, por subculturas, regionais e outras, que permitam caracterizar a cultura política dos jovens brasileiros, em sua complexa e promissora diversidade.

Em suma, os dados levantados em Porto Alegre, em cotejo com os obtidos em Curitiba, e mais ainda, com os da pesquisa nacional de 2003, mostram diferenças contrastantes da cultura política porto-alegrense, no sentido de uma maior politização. Alguns entrevistados naquela cidade chegaram a reconhecer, explicitamente, a influência do Orçamento Participativo no reconhecimento do direito à diferença e à tolerância - além de outras características como o pluralismo, na constituição do que denominaram um "projeto coletivo" para a cidade. 


\section{Considerações finais}

Uma visão superficial dos dados sobre cultura política dessas pesquisas sobre a juventude brasileira sugere, logo à primeira vista, índices elevados de participação política dos jovens, tanto em suas formas de ação convencional como nas não-convencionais. Por exemplo, a identificação partidária dos entrevistados, a aprovação do governo, a confiança nos partidos, a participação em protestos, movimentos sociais, etc. são numericamente equivalentes, ou até superiores, aos observados recentemente entre os jovens da Europa (Cf. Norris, 2003) - e são bem superiores aos observados geralmente no conjunto da população brasileira.

E note-se que nem mencionamos outros dados da pesquisa nacional, como o enorme otimismo dos jovens brasileiros, ao acreditar que "podem mudar o mundo", atribuindo ao seu esforço pessoal e capacidade de inovação, a conquista de um futuro melhor - em sua própria vida, para o seu bairro, e para o país em que vivem. É claro que essas orientações e atitudes positivas podem ter muito a ver com o contexto pós-eleitoral, que suscitou grandes expectativas em toda a população brasileira. De fato, os índices de comparecimento às urnas nas eleições de 2002, declarados pelos jovens entrevistados nessa pesquisa nacional, foram superiores ainda aos elevados índices relatados pelo Superior Tribunal Eleitoral sobre os eleitores em geral.

O aprofundamento dessas análises permitirá chegar a conclusões historicamente fundamentadas - por exemplo, sobre as influências dos contextos regionais e das variáveis demográficas, na formação de variáveis atitudinais, instrumentais e expressivas, subculturas de gênero, classes de renda, escolaridade, e subgrupos de idade entre a juventude. É por isso que os testes sobre valores prioritários, as suas relações com o associativismo, e as alternativas que os jovens buscam, e às vezes realizam, no seu ambiente (e no espaço público em que atuam) será tão fundamental para avaliar também as diversidades de suas opções políticas e perfil ideológico. Pois o extraordinário otimismo - pessoal, social e político - dos jovens pode bem chegar a realizar-se, pelo menos em parte. E é possível verificar se ele fundamenta uma mudança de valores com o restante da sociedade (mesmo que num plano momentâneo e localizado) - não sendo então, apenas, mais uma vez, um ciclo de protesto e euforia, que depois recaia na cinzenta apatia da resignação. 
Para finalizar, alinhamos a seguir os resultados a que chegamos até agora, sobre as relações entre a democratização da cultura política e as políticas de reconhecimento:

1) Curitibanos e porto-alegrenses convergem suas preferências de valores ao redor da justiça, liberdade, desenvolvimento e igualdade, embora os primeiros apontem a disciplina e os segundos o respeito ao meio ambiente, respectivamente, como seu quinto valor prioritário.

2) A ênfase no desenvolvimento e na justiça, presente nas duas cidades, é matizada em Porto Alegre pela ênfase maior na igualdade e na liberdade, que sublinha um contexto participativo, e pela ênfase no meio ambiente, que sublinha o ideal de desenvolvimento sustentável.

3) No caso de Curitiba há uma ênfase no cidadão como portador de direitos e obrigações, em contraste com a ênfase no "outro social", tendencialmente reconhecido em Porto Alegre como participante de um projeto coletivo.

4) Essas ênfases contrastantes podem ser vistas como duas faces complementares do exercício da cidadania, que enfatizam seja o acatamento individual da lei, seja a sua fundamentação e aperfeiçoamento argumentativo, na participação coletiva da esfera pública.

5) Há também uma ênfase significativa no pluralismo político-ideológico, principalmente nas atitudes de apego à tolerância e na disposição ao associativismo da juventude.

6) Tais características da juventude relacionam-se aos diferentes processos de socialização por que passaram, nas duas cidades, e às orientações político-ideológicas contrastantes dos partidos nelas dominantes desde os anos 80 e 90.

7) No caso de Curitiba há uma maior demanda por políticas redistributivas, enquanto em Porto Alegre há uma maior apreciação pelas políticas de reconhecimento, no caso implementadas pelo OP e outras experiências de participação.

8) A pesquisa de 2003 sobre a juventude brasileira, mostra tanto expectativas de políticas sociais redistributivas como de reconhecimento. O equi- 
líbrio entre essas duas ênfases pode variar, bem como suas relações com a democratização da cultura política. Por exemplo, o apoio dos jovens à democracia (43\%) é maior que o revelado pelo Latinobarômetro para o conjunto da população (34\%). E nas cidades de porte médio, muitas delas governadas pelo PT, esse apoio da juventude à democracia sobe a $60 \%$.

9) Como vimos no caso de Porto Alegre, a democratização da cultura política está fortemente relacionada a atitudes de tolerância, pluralismo e reconhecimento do direito à diferença. Cabe esperar que o mesmo ocorra em outras partes do país, em que os governos do PT estão implementando suas políticas de participação. Embora não se possa aduzir uma derivação mecânica entre os dois fenômenos, a sua existência permitirá entender o continuado apoio da população ao governo Lula, independentemente do maior ou menor efeito das políticas simplesmente compensatórias ou redistributivas.

10) Como indicamos no início deste texto, a obra de Fraser sobre a importância das políticas de reconhecimento alerta para a complexidade da análise pendente acerca de suas relações com as políticas redistributivas (ver nota 3 acima). Os indícios levantados aqui, sobre a trajetória do PT e de suas políticas sociais, bem como sobre seus efeitos e relações possíveis na democratização da cultura política, apenas confirmam a necessidade de prosseguir com essa análise, cotejando novos dados e interpretações.

\section{Referências}

ABRAMO, Helena; BRANCO, Paulo (Orgs.). Retratos da juventude brasileira. São Paulo: Fundação Perseu Abramo e Instituto Cidadania (no prelo), 2004b.

DIAS, Marcia Ribeiro. Sob o signo da vontade popular: O Orçamento Participativo e o dilema da Câmara Municipal de Porto Alegre. Rio de Janeiro/Belo Horizonte: IUPERJ/UFMG, 2002.

- Voto e participação política: o impacto do Orçamento Participativo sobre o comportamento eleitoral em Porto Alegre. $\mathrm{CNPq}$ - Projeto de Produtividade em Pesquisa, 2003. 
FRASER, Nancy. Social justice in the age of identity politics: redistribution, recognition, and participation. In: Centre for Theoretical Studies, London: Essex University, 1999.

; HONNETH, Axel. Redistribution or recognition? A political-philosophical exchange. New York: Verso, 2003.

HONNETH, Axel. Invisibility: on the epistemology of recognition. Conferência no CEBRAP, São Paulo, 15/10/03.

- Honneth esquadrinha "déficit sociológico" (Entrevista a Marcos Nobre e Luiz Repa), Folha de São Paulo, E7, 11 out. 2003.

Paulo: Editora 34.

KNIGHT, Alan. Populism and neo-populism in Latin America, especially Mexico. Journal of Latin American Studies, n. 30, p. 223-248, 1998.

KRISCHKE, Paulo J. Aprendendo a democracia na América Latina. Porto Alegre: Edipucrs, 2003a.

. Governo Lula: políticas de reconhecimento e políticas de redistribuição. Cadernos de Pesquisa, n. 47. Doutorado Interdisciplinar em Ciências Humanas, UFSC.

. Cultura política: convergências e diferenças em Porto Alegre e Curitiba. Revista de Ciências Humanas, n. 35 (no prelo), 2004a.

Perfil da juventude brasileira: questões de cultura política e participação democrática. Revista Interthesis, n. 2, DICH/UFSC, $2004 \mathrm{~b}$.

LUCHMANN, Ligia. Possibilidades e limites da democracia deliberativa: a experiência do Orçamento Participativo em Porto Alegre. Tese de Doutorado em Ciências Sociais, UNICAMP, 2002.

MOISÉS, José Álvaro. Os brasileiros e a democracia. As bases sociais da legitimidade democrática. São Paulo: Ática, 1995.

NORRIS, Pippa. Young people and political activism: From the politics of loyalty to the politics of choice? Report for the Council of Europe Symposium, 2003. Disponível em: <www.pippanorris.com>.

PINTO, Celi. Duas formas de fazer política: as eleições municipais em Porto Alegre. Cadernos de Ciência Politica, n. 7. Porto Alegre: UFRGS, 1997.

ROSENFIELD, Denis. A democracia representativa e o Orçamento Participativo. In: LEIS, Hector; ALVES, Caleb (Orgs.). Condição humana e modernidade no Cone Sul. Florianópolis: Cidade Futura, 1995.

SADER, Eder. Quando novos personagens entraram em cena. Rio de Janeiro: Paz e Terra, 1988. 
SCHEDLER, Andreas. Condiciones y racionalidades de la concertación social: una revisión del debate latinoamericano. Documento de Trabajo. Série Estudios Sociales, Santiago: FLACSO, n. 23, 1992.

SIERRA, Geronimo; BERNALES, Manuel (Orgs.). Democracia, gobernanza y desarrollo en el Mercosur. Montevidéu: UNESCO/FLACSO, 2004.

TORRE, Carlos de la. Populist Redemption and the Unfinished Democratization of Latin America. Constellations, 5(1): 85-95, 1998.

TUMOLO, Paulo. Da contestação à conformação. A formação sindical da CUT e a reestruturação capitalista. Campinas: Editora da Unicamp, 2002. 